\title{
Teaching As A Profession
}

\author{
Shirley N. Robards, University of Tulsa
}

\section{THE IMAGE OF THE PROFESSION}

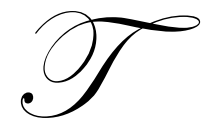

he image of the schools and the teaching profession according to the media is usually negative. The negative picture is one reflecting the social problems of society and the failure of schools to educate, that is, drop-outs, teenage pregnancies, substance abuse, guns, knives, and attacks on students and teachers. Occasionally, the positive picture is communicated illustrating the success of the school and its professionals. For example, on channel 5 in New York City on May 24, 1990, the evening news featured Seward Park High School as described in Small Victories by Samuel Freedman. The short interview by the news staff included a successful student, Carlos, who had graduated from Seward Park High School and had gone to college. Also in the interview was Jessica Siegal, a former English and journalism teacher at the school. Success in school, according to Carlos, can co-exist with failures and drop-outs. The teacher was the key to making dreams come true. Teachers help students to realize that their dreams can become realities. These professionals teach students to not only acquire basic skills, such as writing, but also help students acquire an identity of caring for self and others as well as succeeding in life. Great professionals make great schools, but as the teacher goes so goes the school.

Recently during a severe ice storm in Tulsa, the I began a conversation with a Wal-Mart customer waiting in line to check-out. The lady was purchasing pencils, pens and paper. I asked if the lady was a teacher and she said, "Yes, I teach math at one of the area middle schools." After a week of no school, the teacher indicated that she was buying supplies to use at her home. Her students were invited to the make-up sessions in order to catch with the school district's curriculum and pacing calendar. What a true professional willing to go the extra mile for her students.

\section{ROLE OF EDUCATION IN A DEMOCRACY}

Education is important to all cultures. A Chinese proverb says if you want to remember someone for a year, you plant corn; if you want to remember someone for 10 years, you plant a tree; if you want to remember someone for 100 years, you educate. For 40 centuries we have been lecturing, memorizing facts, and using the board of education.

Education is central to our democracy. Its foundation should be its schools, colleges and universities. If we want the United States and other countries to continuing thriving, we must recognize that we have the same principles in the Constitution that Thomas Jefferson described. Additional support for the importance of education in a democratic society was written by George S. Counts in Education for a Democracy who concluded that the survival of every form of society rests upon education and that the survival of every complex society rests upon a system of organized education that is staffed by competent professionals.

\section{EXTERNAL AND INTERNAL VIEWS OF THE PROFESSION}

Both externally and internally, teaching is a troubled profession. We are professional educators surrounded by a sea of indifference. We are human beings who respond emotionally in crises. We point fingers at others for our problems. Schools and teachers are being pulled down and trampled in the mud. Although we do not agree, a revered profession has become a scapegoat for the social and political problems in society.

American schools and teachers are faced with new challenges that were never imagined 100 years ago. Many academicians have written about the issue of the professional status of teaching and teacher educators. But it is to Horace Mann that we find some of the earliest and most supportive arguments for teaching as a profession in the United States. Many educators and professionals have worked diligently for those conditions that would develop teaching as a profession. The characteristics of a professional included: (a) careful selections of personnel, (b) well- 
designed accredited undergraduate and advanced preparations programs, (c) increased status, (d) increased authority, (e) licensing and (f) examinations

The early professional educators not only believed that schools demanded its own kind of teachers, thoroughly committed to the values of the culture, but also they believed that professional schools of education were different from the traditionally oriented academic institutions. Dean James Russell at Teachers College in 1902 pointed out that the College was the "professional school of Columbia University for the advanced professional training of teachers" and that its place was similar to the other professional schools of law, medicine, and applied science. It was assumed from the very beginning that teachers would have collegiate preparation, including both academic knowledge and professional knowledge and would complete pre requisites for entrance into the profession. This assumption has caused tension and conflict for many years.

On the one hand, there is the assumption for the public to set policy, determine direction for schools, and provide financial support that represents control of education. This local and state control of schooling has dominated education for years, and the key actors are school boards and administrators rather than teachers. Other writers argue there is the role of the teaching profession to govern its own work, set standards, determine the nature of the knowledge base, and help prepare graduates to function effectively in school settings.

\section{PROFESSIONALISM}

Is teaching a profession or a semi-profession? Almost 25 years ago, the public and professional teacher educators focused on improving the teaching profession with definitions having different connotations. One of the recurring themes of the reform reports, writes Lee Shulman (1985, p. 313), was the professionalization of teaching, or the elevation of teaching to a higher status, that is, "a more respected, more responsible, more rewarding and rewarded occupation." Linda Darling-Hammond noted that professionalization was not static or a state of being into which an occupation may be classified, but may be represented on "a continuum representing the way members of an occupation share (a) a practice in exercising that knowledge on behalf of clients." In the case of policy makers "professional" often means that a teacher is one "who does things right" and follows district policies rather than one "who does the right thing."

Sociology researchers studying professionals as a subgroup of the workforce suggest the true professionals are characterized in six ways Jack Frymire, 1995, pp. 49-50, At The Threshold of the Millennium.

First, professionals not only provide service to others, but also help other people. For example, the service is essential. If a 9 year-old child has a ruptured appendix; he/she needs the assistance of a pediatric surgeon and can not resolve the problem alone.

Second, professionals have special skills and methods that they employ in helping their clients and these skills and methods are taught in the professional schools. For example, no one is born with the knowledge and skills to counsel a youth addicted to drugs, draw up a family trust, and teach a students with learning disabilities, a speech problem or deficiencies in reading.

Third, professionals base what they do on the best research practices available. For example, the orthopedic surgeon practicing hip replacement surgery may do the procedures differently over a two year period because of advances in the field.

Fourth, professional make decision that affect other people, and the people who are affected usually do not know if the decisions are correct. For example, a cardiologist may tell a patent that he/she needs open heart surgery or stints in the coronary arteries, but the patient may not know if the recommendations are right or wrong. The patient must have trust in what the professional says and on the track record of the physician. 
Fifth, because of a professional code of ethics, the client expects the professional to practice under the highest standards of a particular profession. For example an attorney in one state working with a second attorney in another state expects the relationship to be professional, ethical and effective.

Sixth, 'true professionals' use their professional organizations to make sure that every member of the group adheres to the highest ethical principles. For example, in a recent situation where a dentist was selling prescriptions for pain medication from his home, the dentist was denied the right to practice.

As educators looking at the characteristics and criteria for a profession, we realize that teaching is not yet a profession. But that means that we do not give up, but continue to work toward the goal of professionalism..

\section{IMPACT OF THE REFORMS}

Over the past 100 years, teaching has been widely proclaimed by each generation as a profession. In times of teacher shortages, standards have been reduced and emergency or alternative licenses were issued to meet staffing needs. Meanwhile in times of oversupply, standards for teaching were increased with most states enacting legislation to regulate what should be taught, how it should be taught, and who should teach? Mary Futrell, past president of the National Education Association, found that between 1983 and 1985 more than 700 statutes were passed by state legislatures imposing control and increased regulations for teachers. These controls from outside the professional dampened the spirits of many professional educators who had more responsibility, but less recognition and empowerment.

For the past 15 years, policy makers and educators have been faced with implementing changes that require blending national goals and standards with local creativity and flexibility in order to restructure the schools for all students to reach their potential, regardless of ethnic differences, linguistic backgrounds, or socio-economic status. These reforms include, benchmark testing in schools to meet the requirements of No Child Left Behind, teacher accreditation standards, certification and licensing changes, such as the National Teaching Board.

William Glasses notes that schools will not change until teachers develop a new philosophy and see themselves in a restructured setting where the teachers are not performing like factory managers, but serve as facilitators, resource people and coaches. Likewise, students would become the workers who take more responsibility for their learning. Will Richardson, speaking in November 2007 at the Kappa Delta Pi convocation noted that in today's world different ways of communicating opens up a new work of learning. Teachers are connectors between their students and the experts around the world.

\section{STRATEGIES FOR CHANGE}

Our response to change can be one of nostalgia and a yearning for the return of the past when schools were in the hands of the local school boards or we can forge onward. The latter choice, according to Albert Shanker, of the American Federation of Teachers, means restructuring the schools and empowering teachers-more control of their working conditions, the opportunity to try various teaching strategies, more time to assist learners and small groups, more opportunity to share ideas with colleagues, and time to develop curriculum materials . Through the series of social, pedagogical, political, and technological changes occurring in the past 25 years, the teaching professional is continuing to evolve. Issues that continue to challenge the professions include:

1. Additional sources of funding for school and increasing teacher salaries

2. Recruiting the brightest and the best to teach

3. Strengthening the connection between the family and the school

4. Revitalizing and funding of teacher preparation to prepare personnel for new roles

a. Supporting beginning teacher programs

b. Developing professional development schools

c. Clarify the impact of national certification on the profession

d. Review the impact of Alternative Certification on the profession 
5. Supporting collaboration and partnerships with other organizations and community agencies

Wagoner in his book, Jefferson and Education writes that educators should followed the wisdom of Jefferson who believed that as each generation becomes "more developed, more enlightened, as new discoveries are made, new truths disclosed and knowledge changes," the profession of teaching must also change to keep pace. To prepare tomorrow's adults to live in an interdependent, global society, educators must march bravely forward. Despite 'a jump-start' strategy of each wave of reform, the teaching profession must continue to improve.

As educators, we must take an active role in reforming and restructuring the schools. John Gardner notes that a nation is never finished; it recreates for each generation. Professionalism for educators can not be built like the pyramids. It must be rebuilt and recreated by committed, caring professionals who believe that we have not only the opportunity to make a difference, but also that what we do does make a difference in the lives of students. This true professional spirit enables us to continue to improve the profession and to help learners to protect their vision of life, of liberty, and the pursuit of happiness - the education of all.

\section{AUTHOR INFORMATION}

Dr. Shirley N. Robards is the Coordinator of Field Services and Director of the TU GEAR UP Project. The GEAR UP activities at The University of Tulsa include: tutoring, professional development and a summer academy. She is an associate professor in the School of Education and teaches field-based courses in elementary reading and math methods. Dr. Robards is also a certified trainer for workshops in helping teachers focus on teacher expectations and student achievement. She has graduate degrees from Western Kentucky University and Indiana University. She is a past president of the Association of Teacher Educators and a former international vice president of Phi Delta Kappa.

\section{BIBLIOGRAPHY}

1. A Nation At Risk: The Imperative for Educational Reform (1983). National Commission on Excellence in Education. Washington, D.C.: U.S. Department of Education.

2. Breault, Donna Adair and Rick Breault (2005). Experiencing Dewey: Insights For Today's Classroom. Indianapolis, IN: Kappa Delta Pi,159 pp.

3. Day, Barbara D. (1999). Teaching and Learning in the New Millennium. Indianapolis, IN: Kappa Delta $\mathrm{Pi}, 159 \mathrm{pp}$.

4. Freedman, S.G.(1984, 1990). Small Victories: The Real World of a Teacher, Her Students and Their High School. New York: Harper Perennial Publishers, 431pp.

5. Howsam, R. B. Chairman and others (1976). Educating a Profession. Washington, D. C.: American Association of Colleges for Teacher Education, $171 \mathrm{pp}$.

6. Robards, S. N. (1990). The Professionalization of Teaching, Association of Teacher Educators, Summer Workshop speech, Baltimore, MD.

7. Steffy, Betty and others (2000). Life Cycle of the Career Teacher. Indianapolis, IN: Kappa Delta Pi and Corwin Press, 128 pp.

8. Teacher Professionalization and Teacher Commitment: A Multilevel Analysis (1997). Washington, D. C.: U.S. Dept. of Education.

9. Walling, D. R. Editor (1995). At the Threshold of the Millennium. Bloomington, IN: Phi Delta Kappa Educational Foundation, 116pp.

10. Wagoner, Jr., J.L. (2004). Jefferson and Education. Chapel Hill, NC: University of North Carolina Press, $168 \mathrm{pp}$. 